Article

\title{
GeneAnalytics Pathway Analysis and Genetic Overlap among Autism Spectrum Disorder, Bipolar Disorder and Schizophrenia
}

\author{
Naveen S. Khanzada ${ }^{1}$, Merlin G. Butler ${ }^{1,2}$ and Ann M. Manzardo ${ }^{1, *}$ \\ 1 Department of Psychiatry and Behavioral Sciences, University of Kansas Medical Center, Kansas City, \\ KS 66160, USA; nkhanzada@kumc.edu (N.S.K.); mbutler4@kumc.edu (M.G.B.) \\ 2 Department of Pediatrics, University of Kansas Medical Center, Kansas City, KS 66160, USA \\ * Correspondence: amanzardo@kumc.edu; Tel.: +1-913-588-6473 \\ Academic Editor: William Chi-shing Cho \\ Received: 18 January 2017; Accepted: 23 February 2017; Published: 28 February 2017
}

\begin{abstract}
Bipolar disorder (BPD) and schizophrenia (SCH) show similar neuropsychiatric behavioral disturbances, including impaired social interaction and communication, seen in autism spectrum disorder (ASD) with multiple overlapping genetic and environmental influences implicated in risk and course of illness. GeneAnalytics software was used for pathway analysis and genetic profiling to characterize common susceptibility genes obtained from published lists for ASD (792 genes), BPD (290 genes) and SCH (560 genes). Rank scores were derived from the number and nature of overlapping genes, gene-disease association, tissue specificity and gene functions subdivided into categories (e.g., diseases, tissues or functional pathways). Twenty-three genes were common to all three disorders and mapped to nine biological Superpathways including Circadian entrainment (10 genes, score $=37.0)$, Amphetamine addiction (five genes, score $=24.2$ ), and Sudden infant death syndrome (six genes, score $=24.1)$. Brain tissues included the medulla oblongata (11 genes, score $=2.1)$, thalamus $(10$ genes, score $=2.0)$ and hypothalamus (nine genes, score $=2.0)$ with six common genes (BDNF, DRD2, CHRNA7, HTR2A, SLC6A3, and TPH2). Overlapping genes impacted dopamine and serotonin homeostasis and signal transduction pathways, impacting mood, behavior and physical activity level. Converging effects on pathways governing circadian rhythms support a core etiological relationship between neuropsychiatric illnesses and sleep disruption with hypoxia and central brain stem dysfunction.
\end{abstract}

Keywords: mental illness; genetic profiling; GeneAnalytics molecular pathway analysis; circadian entrainment

\section{Introduction}

Severe neuropsychiatric disorders collectively present with similar behavioral, social, cognitive and perceptual disturbances including autism spectrum disorder (ASD). ASD includes classical autism, Asperger syndrome and pervasive developmental disorder with problems in social interaction and communication or repetitive behavior. Schizophrenia $(\mathrm{SCH})$ presents with delusions, hallucinations, disorganized thinking and behavior with negative symptoms. Bipolar disorder (BPD) is considered a developmental disorder characterized by progressive cognitive impairment, residual symptoms, sleep disturbance, and emotional dysregulations with cycles of depression and mania. Schizophrenia and bipolar disorders share many common traits with ASD, including social and cognitive dysfunction and impaired ability to function, live and work independently [1]. Considerable overlap has been identified between the molecular mechanisms implicated in the etiology of schizophrenia, bipolar disorder, and autism, suggesting similar root causes [2]. Up to $30 \%$ of patients diagnosed with ASD during childhood 
will develop schizophrenia during adulthood [3]. Further, the presence of schizophrenia or bipolar disorder in first-degree relatives is a consistent and significant risk factor for ASD [4]. These three neuropsychiatric illnesses have complex inheritance patterns with $>80 \%$ estimate for each disorder with multiple genetic and environmental factors influencing disease risk and course [2,4].

A recent large collaborative genetic study of families with schizophrenia and ASD showed significant overlap in candidate genes and susceptibility regions for both disorders using traditional karyotyping, genome-wide association studies (GWAS) and comparative genome hybridization (CGH) analyses by identifying chromosomal deletions and duplications in individuals with ASD [5-8]. ASD and SCH risk alleles appear to impact growth-signaling pathways with autism associated with loss of function in many genes [9-11], whereas schizophrenia tends to be associated with reduced function or activity of genes that up-regulate growth-related pathways [12-16].

Cytogenetic, linkage and association studies have identified common copy number variants (CNVs, deletions, duplications) between ASD and SCH which may produce dosage-dependent gain or loss of expression of genes contributing to phenotypic variation in presentation and course of illness. A large number of autism-specific $C N V$ s have been found but with low recurrence $(<1 \%)$ and they show a high level of genetic heterogeneity. For example, when the 15q11.2 BP1-BP2 region or 15q13.3 band contains a deletion or duplication in patients, then autism or a variety of neuropsychiatric traits including schizophrenia are identified [3,17-19]. Gene expression disturbances were found using postmortem cortical brain tissue from patients with autism, schizophrenia and bipolar disorder and they have shown a high correlation between the transcriptomes of ASD and schizophrenia, but not in BPD [5]. Hence, a large number of possible genetic and environmental factors do influence disease risk, expression and treatment.

Herein, we use the GeneAnalytics [20] program pathway analysis to further profile and characterize the underlying molecular architecture of clinically and etiologically relevant genes common to ASD [21], bipolar disorder [22] and schizophrenia [23] and associated diseases.

\section{Results}

The original gene lists reported in the literature included 792 genes for ASD [21], 290 genes for bipolar disorder [22] and 560 genes for schizophrenia [23], and of these, 23 genes were found in common in all three conditions (see Table 1). Functional analysis of the 23 genes identified from the submitted list of genes showed a high match for schizophrenia $(17$ genes, score $=15.1)$ with medium-match scores representing 25 other disorders including bipolar disorder (nine genes, score $=9.6$ ) and autism spectrum disorder $(10$ genes, score $=9.1)$. Additional diseases identified were related to disorders of mental health including mood and personality disorders (see Table 2A). Tissues and cell types profiled for these 23 overlapping genes identified five common types of brain tissues which achieved high match scores (see Table 2B). These included the medulla oblongata (11 genes, score $=2.1$ ), thalamus $(10$ genes, score $=2.0)$, hypothalamus (nine genes, score $=2.0)$, hippocampus (nine genes, score $=1.9)$ and cerebellum (eight genes, score = 1.9). Six (BDNF, DRD2, CHRNA7, HTR2A, SLC6A3, and TPH2) of the overlapping genes were matched to all five tissues types. Sixteen of the overlapping genes matched to a total of 36 Biological Superpathways with a total of nine Superpathways achieving significantly high match scores according to the GeneAnalytics pathway analysis and algorithm [20]. The Circadian entrainment pathway showed the highest match score involving 10 genes (score $=37.0$ ), followed by Amphetamine addiction involving five genes (score $=24.3$ ) and Sudden infant death syndrome (SIDS) susceptibility pathways (six genes, score $=24.1)($ see Table 3$)$. 
Table 1. Twenty-three clinically relevant genes common to ASD, BPD and schizophrenia.

\begin{tabular}{|c|c|c|}
\hline Gene Symbol & Gene Name & Chromosome Location \\
\hline$B D N F$ & Brain-derived neurotrophic factor & $11 \mathrm{p} 14.1$ \\
\hline ANK3 & Ankyrin 3 & $10 \mathrm{q} 21.2$ \\
\hline CACNA1C & $\mathrm{Ca}^{2}+$ channel, voltage-dependent, $\mathrm{L}$ type, $\alpha 1 \mathrm{C}$ subunit & 12p13.33 \\
\hline CACNB2 & $\mathrm{Ca}+$ channel, voltage dependent, $\beta 2$ subunit & $10 \mathrm{p} 12.33$ \\
\hline CHRNA7 & Cholinergic receptor, nicotinic, $\alpha 7$ (neuronal) & $15 q 13.3$ \\
\hline CNTNAP5 & Contactin associated protein-like 5 & $2 \mathrm{q} 14.3$ \\
\hline CSMD1 & CUB and sushi multiple domains 1 & $8 \mathrm{p} 23.2$ \\
\hline DISC1 & Disruption in schizophrenia 1 & $1 \mathrm{q} 42.2$ \\
\hline DPP10 & Dipeptidyl-peptidase 10 (non-functional) & 2q14.1 \\
\hline DRD2 & Dopamine receptor D2 & $11 \mathrm{q} 23.2$ \\
\hline FOXP2 & Forkhead box P2 & $7 \mathrm{q} 31.1$ \\
\hline GSK3B & Glycogen synthase kinase $3 \beta$ & $3 q 13.33$ \\
\hline HTR2A & 5-Hydroxytryptamine (serotonin) receptor 2A, G-protein-coupled & 13q14.2 \\
\hline$M A O A$ & Monoamine oxidase A & Xp11.3 \\
\hline MTHFR & Methylenetetrahydrofolate reductase & $1 \mathrm{p} 36.22$ \\
\hline NOS1AP & Nitric oxide synthase 1 (neuronal) adaptor protein & $1 \mathrm{q} 23.3$ \\
\hline NRG1 & Neuregulin 1 & $8 \mathrm{p} 12$ \\
\hline$P D E 4 B$ & Phosphodiesterase 4B, CAMP-specific & $1 \mathrm{p} 31.3$ \\
\hline$S L C 6 A 3$ & Solute carrier family 6 (neurotransmitter transporter, dopamine), member 3 & 5p15.33 \\
\hline SYN3 & Synapsin III & $22 q 12.3$ \\
\hline TCF4 & Transcription factor 4 & $18 \mathrm{q} 21.1$ \\
\hline TPH2 & Tryptophan hydroxylase 2 & $12 \mathrm{q} 21.1$ \\
\hline ZNF804A & Zinc finger protein $804 \mathrm{~A}$ & $2 q 32.1$ \\
\hline
\end{tabular}

Table 2. GeneAnalytics program mapping of diseases, tissues and cells that were significantly matched to 23 overlapping genes for autism spectrum disorder, bipolar disorder and schizophrenia.

\begin{tabular}{|c|c|c|c|}
\hline A. Diseases & Genes Matched to Disease Type (Highmatch Score) & $\begin{array}{l}\text { No. of Genes in } \\
\text { Disease Type }\end{array}$ & Score \\
\hline Schizophrenia & $\begin{array}{c}\text { ANK3, BDNF, CACNA1C, CHRNA7, DISC1, NRG1, DRD2, } \\
\text { GSK3B, HTR2A, MAOA, MTHFR, NOS1AP, PDE4B, } \\
\text { SLC6A3, SYN3, TPH2, ZNF804A }\end{array}$ & 249 & 15.1 \\
\hline \multicolumn{4}{|c|}{ (Mediummatch scores > 6.0) } \\
\hline Bipolar disorder & $\begin{array}{c}\text { BDNF, DISC1, DRD2, GSK3B, HTR2A, MAOA, NRG1, } \\
\text { SLC6A3, ZNF804A }\end{array}$ & 39 & 9.6 \\
\hline Autism spectrum disorder & $\begin{array}{c}\text { BDNF, CHRNA7, DISC1, DRD2, FOXP2, HTR2A, MAOA, } \\
\text { MTHFR, SLC6A3, TPH2 }\end{array}$ & 103 & 9.1 \\
\hline Disease of mental health & $\begin{array}{c}B D N F, D I S C 1, D R D 2, H T R 2 A, M A O A, N R G 1, \\
\text { SLC6A3, ZNF804A }\end{array}$ & 57 & 8.0 \\
\hline $\begin{array}{l}\text { Attention deficit } \\
\text { hyperactivity disorder }\end{array}$ & $\begin{array}{c}\text { BDNF, CHRNA7, DRD2, HTR2A, MAOA, SLC6A3, } \\
\text { TPH2, ZNF804A }\end{array}$ & 63 & 7.8 \\
\hline Mood disorder & BDNF, CACNA1C, DISC1, DRD2, HTR2A, MAOA, TPH2 & 31 & 7.7 \\
\hline Psychotic disorder & BDNF, CHRNA7, DISC1, DRD2, HTR2A, NRG1, SLC6A3 & 37 & 7.5 \\
\hline Anxiety disorder & BDNF, DRD2, HTR2A, MAOA, SLC6A3, TPH2 & 21 & 7.1 \\
\hline Obsessive compulsive disorder & BDNF, DRD2, HTR2A, MAOA, SLC6A3, TPH2 & 29 & 6.8 \\
\hline Personality disorder & DRD2, HTR2A, MAOA, SLC6A3, TPH2 & 14 & 6.4 \\
\hline B. Tissues and Cells & Genes Matched to Tissues and Cells & $\begin{array}{l}\text { No. of Genes in } \\
\text { Tissues And Cells }\end{array}$ & Score \\
\hline Medulla oblongata & $\begin{array}{c}\text { BDNF, CHRNA7, DRD2, FOXP2, HTR2A, MAOA, NRG1, } \\
\text { PDE4B, SLC6A3, TCF4, TPH2 }\end{array}$ & 2179 & 2.1 \\
\hline Thalamus & $\begin{array}{c}\text { BDNF, CHRNA7, DRD2, HTR2A, MTHFR, PDE4B, } \\
\text { SLC6A3, TCF4, TPH2 }\end{array}$ & 1736 & 2.0 \\
\hline Hypothalamus & $\begin{array}{c}\text { BDNF, CHRNA7, DRD2, FOXP2, HTR2A, MTHFR, PDE4B, } \\
\text { SLC6A3, TCF4, TPH2 }\end{array}$ & 1666 & 2.0 \\
\hline Hippocampus & $\begin{array}{c}\text { ANK3, BDNF, CHRNA7, DISC1, DRD2, FOXP2, HTR2A, } \\
\text { SLC6A3, TPH2 }\end{array}$ & 3335 & 1.9 \\
\hline Cerebellum & $\begin{array}{c}\text { ANK3, BDNF, CHRNA7, DRD2, FOXP2, HTR2A, } \\
\text { SLC6A3, TPH2 }\end{array}$ & 2609 & 1.9 \\
\hline
\end{tabular}


Table 3. GeneAnalytics program mapping of superpathways with high match scores for 23 overlapping genes for autism spectrum disorder, bipolar disorder and schizophrenia.

\begin{tabular}{|c|c|c|c|}
\hline Superpathways & Genes Matched to Superpathways & $\begin{array}{l}\text { No. of Genes in } \\
\text { Superpathways }\end{array}$ & Score \\
\hline Circadian entrainment & $\begin{array}{c}\text { SLC6A3, GSK3B, HTR2A, MAOA, NOS1AP, PDE4B, } \\
\text { TPH2, CACNA1C, CHRNA7, DRD2 }\end{array}$ & 390 & 37.0 \\
\hline Amphetamine addiction & SLC6A3, MAOA, BDNF, CACNA1C, DRD2 & 87 & 24.3 \\
\hline SID susceptibility pathways & HTR2A, MAOA, NOS1AP, TPH2, BDNF, CHRNA7 & 185 & 24.1 \\
\hline $\begin{array}{l}\text { Selective serotonin reuptake } \\
\text { inhibitor pathways }\end{array}$ & HTR2A, MAOA, TPH2 & 29 & 17.5 \\
\hline Monoamine transport & SLC6A3, MAOA, TPH2 & 36 & 16.6 \\
\hline $\begin{array}{l}\text { Transmission across } \\
\text { chemical synapses }\end{array}$ & SLC6A3, MAOA, SYN3, CACNB2, CHRNA7 & 316 & 15.2 \\
\hline CREB pathways & $\begin{array}{c}\text { HTR2A, NRG1, BDNF, CACNA1C, } \\
\text { CACNB2, CHRNA7 }\end{array}$ & 562 & 14.9 \\
\hline $\begin{array}{l}\text { Neurotransmitter clearance in the } \\
\text { synaptic cleft }\end{array}$ & $S L C 6 A 3, M A O A$ & 8 & 14.6 \\
\hline CAMP signaling pathways & PDE4B, BDNF, CACNA1C, DRD2 & 211 & 13.4 \\
\hline
\end{tabular}

The remaining Superpathways identified did emphasize monoamine signaling and cellular re-uptake/transport. There was little intrinsic overlap between the 36 biological Superpathways with only one gene (DRD2) common to all nine Superpathways.

Examination of gene ontology pathways identified 17 genes that matched to a total of 32 GO-molecular functions but high match scores were found for only three molecular functions involving six genes: Serotonin binding with two genes (HTR2, MAOA) out of nine total pathway genes, score $=14.3$; Dopamine binding with two genes $(S L C 6 A 3, D R D 2)$ out of 10 total pathway genes, score $=14)$ and High Voltage-gated Calcium Channel Activity with two genes $(C A C N A 1 C, C A C N B 2)$ out of 10 total pathway genes, score $=14$. The 23 overlapping genes mapped to a total of 55 GO-biological processes with high match scores identified for 16 biological processes involving 19 genes (see Table 4). These processes involved a variety of behavioral constructs including axon guidance, synaptic transmission, and particularly the activity of ion channels and dopamine homeostasis.

Table 4. GeneAnalytics program mapping of gene ontology (GO) biological processes with high match scores to 23 overlapping genes for autism spectrum disorder, bipolar disorder and schizophrenia.

\begin{tabular}{|c|c|c|c|}
\hline GO-Biological Processes & $\begin{array}{c}\text { Genes Matched to GO-Biological } \\
\text { Processes }\end{array}$ & $\begin{array}{c}\text { No. of Genes in } \\
\text { GO-Biological Processes }\end{array}$ & Score \\
\hline Startle response & NRG1, CSMD1, DRD2 & 20 & 19.1 \\
\hline Cellular calcium ion homeostasis & HTR2A, CACNA1C, CHRNA7, DRD2 & 107 & 17.2 \\
\hline Synaptic transmission & $\begin{array}{c}\text { SLC6A3, HTR2A, MAOA, CACNA1C, } \\
\text { CACNB2, CHRNA7 }\end{array}$ & 432 & 17.0 \\
\hline Axon guidance & $\begin{array}{l}\text { GSK3B, NRG1, ANK3, BDNF, } \\
\text { CACNA1C, CACNB2 }\end{array}$ & 537 & 15.3 \\
\hline Synapse assembly & NRG1, BDNF, DRD2 & 52 & 15.0 \\
\hline $\begin{array}{c}\text { Regulation of high voltage-gated calcium } \\
\text { channel activity }\end{array}$ & NOS1AP, PDE4B & 7 & 15.0 \\
\hline Adenohypophysis development & $S L C 6 A 3, D R D 2$ & 9 & 14.3 \\
\hline Regulation of synaptic transmission, GABAergic & SYN3, DRD2 & 10 & 14.0 \\
\hline Behavioral response to ethanol & CHRNA7, DRD2 & 11 & 13.7 \\
\hline Regulation of dopamine secretion & SLC6A3, CHRNA7 & 11 & 13.7 \\
\hline Dopamine biosynthetic process & HTR2A, DRD2 & 12 & 13.4 \\
\hline
\end{tabular}


A total of 106 phenotypes were mapped to the 23 overlapping genes with 36 phenotypes involving 18 genes having high match scores (see Table 5). The highest-matched phenotypes were behavioral despair (four genes, score $=24.8$ ), hypoactivity (seven genes, score $=24.4$ ), abnormal serotonin levels (four genes, score $=24.1$ ) and abnormal response to novel objects (four genes, score $=22.2$ ). Additionally, phenotypes impacted GABAergic neuron morphology, synaptic transmission and response to hypoxia and risk of death.

Table 5. GeneAnalytics profiling of high match score phenotypes to 23 overlapping genes for autism spectrum disorder, bipolar disorder and schizophrenia.

\begin{tabular}{|c|c|c|c|}
\hline Phenotypes & Genes Matched to Phenotypes & No. of Genes & Score \\
\hline Behavioral despair & GSK3B, CACNA1C, CSMD1, DISC1 & 28 & 24.8 \\
\hline Hypoactivity & MAOA, FOXP2, ANK3, BDNF, CACNA1C, CHRNA7, DRD2 & 314 & 24.4 \\
\hline Abnormal serotonin level & $M A O A, F O X P 2, T P H 2, B D N F$ & 32 & 24.1 \\
\hline Abnormal response to novel object & SLC6A3, FOXP2, TPH2, DISC1 & 44 & 22.2 \\
\hline $\begin{array}{l}\text { Abnormal GABAergic } \\
\text { neuron morphology }\end{array}$ & $B D N F, C H R N A 7, D R D 2$ & 11 & 21.7 \\
\hline Abnormal prepulse inhibition & NRG1, DISC1, DRD2 & 14 & 20.7 \\
\hline Abnormal social Investigation & $M A O A, S Y N 3, C A C N A 1 C, D I S C 1$ & 14 & 20.7 \\
\hline Increase aggression towards males & $M A O A, T P H 2, B D N F$ & 64 & 20.1 \\
\hline Small cerebellum & MTHFR, FOXP2, ANK3, DISC1 & 67 & 19.8 \\
\hline $\begin{array}{l}\text { Decrease exploration in } \\
\text { new environment }\end{array}$ & GSK3B, FOXP2, BDNF, CACNA1C & 79 & 18.9 \\
\hline Abnormal CNS synaptic transmission & SLC6A3, BDNF, CACNA1C, DRD2 & 79 & 18.9 \\
\hline Premature death & $\begin{array}{c}\text { SLC6A3, MTHFR, FOXP2, ANK3, TPH2, BDNF, } \\
\text { CACNA1C, DRD2 }\end{array}$ & 830 & 18.6 \\
\hline Decrease startle reflex & FOXP2, CSMD1, DISC1, DRD2 & 84 & 18.6 \\
\hline Decrease anxiety-related response & HTR2A, CHRNA7, DISC1, DRD2 & 89 & 18.2 \\
\hline Increase dopamine level & SLC6A3, MAOA, FOXP2 & 31 & 17.2 \\
\hline Abnormal vocalization & FOXP2, CACNA1C, DRD2 & 37 & 16.5 \\
\hline Hyperactivity & SLC6A3, NRG1, BDNF, CSMD1, DISC1 & 272 & 16.3 \\
\hline Increased thigmotaxis & SLC6A3, CACNA1C, CSMD1 & 45 & 15.6 \\
\hline $\begin{array}{l}\text { Abnormal serotonergic neuron } \\
\text { morphology }\end{array}$ & TPH2, BDNF & 6 & 15.4 \\
\hline Abnormal response to novel odor & $S L C 6 A 3, D R D 2$ & 6 & 15.4 \\
\hline $\begin{array}{l}\text { Abnormal latent inhibition } \\
\text { of conditioning }\end{array}$ & DISC1, DRD2 & 6 & 15.4 \\
\hline Impaired coordination & SLC6A3, FOXP2, BDNF, CACNA1C, DRD2 & 309 & 15.4 \\
\hline $\begin{array}{c}\text { Abnormal } \\
\text { learning/memory/conditioning }\end{array}$ & GSK3B, CACNA1C, DISC1 & 49 & 15.3 \\
\hline Limp posture & NRG1, DRD2 & 7 & 15.0 \\
\hline Decreased serotonin Level & TPH2, DISC1 & 7 & 15.0 \\
\hline Postnatal growth retardation & SLC6A3, MTHFR, FOXP2, TPH2, BDNF, DRD2 & 581 & 14.6 \\
\hline Abnormal pituitary gland physiology & $S L C 6 A 3, D R D 2$ & 8 & 14.6 \\
\hline $\begin{array}{l}\text { Abnormal inhibitory postsynaptic } \\
\text { currents }\end{array}$ & $S L C 6 A 3, S Y N 3, B D N F$ & 60 & 14.4 \\
\hline Small nodose ganglion & NRG1, BDNF & 9 & 14.3 \\
\hline Complete postnatal lethality & FOXP2, ANK3, TCF4, BDNF, CACNA1C & 375 & 14.1 \\
\hline Small petrosal ganglion & NRG1, BDNF & 10 & 14.0 \\
\hline Decreased somatotroph cell number & $S L C 6 A 3, D R D 2$ & 11 & 13.7 \\
\hline Abnormal grooming behavior & $S L C 6 A 3, M A O A$ & 11 & 13.7 \\
\hline $\begin{array}{l}\text { Abnormal excitatory } \\
\text { postsynaptic currents }\end{array}$ & NRG1, SYN3, DRD2 & 72 & 13.6 \\
\hline $\begin{array}{l}\text { Decreased left ventricle } \\
\text { systolic pressure }\end{array}$ & $M A O A, N R G 1$ & 12 & 13.4 \\
\hline Hunched posture & $M A O A, B D N F, D R D 2$ & 78 & 13.3 \\
\hline
\end{tabular}

\section{Discussion}

The molecular and genetic architecture of ASD, BPD and SCH with the identified 23 overlapping candidate susceptibility genes common to the three neuropsychiatric illnesses were analyzed 
to assess shared etiological factors and phenotypes to facilitate mechanistic understanding and potential development of new treatment approaches. Interestingly, the genetic architecture of the overlapping genes for the three disorders converged on brain structures (e.g., medulla oblongata, thalamus), neurotransmitter systems (e.g., dopamine, serotonin) and signal transduction pathways primarily involved in the regulation of circadian oscillations and sleep disturbances. GO-molecular processes were mapped to the neurotransmitter pathways (dopamine, andserotonin) and ion channels (high voltage-gated calcium channels) implicated in mood, addiction and psychotic disorders with regulatory function and expression in brain centers controlling Circadian entrainment.

The human thalamus, hypothalamus and hippocampus have been extensively targeted in relation to relaying and processing sensory and motor information, as well as regulating consciousness and sleep [24]. The central and peripheral circadian molecular clock is entrained through a complex and highly regulated molecular cascade in the suprachiasmatic nuclei $(\mathrm{SCN})$ of the hypothalamus driven by the cyclical expression of PER and CRY [25-27]. The master lists of susceptibility genes for BPD and SCH contain CLOCK, an integral part of the Circadian entrainment pathway, and the identified ASD master gene list contains additional circadian-regulatory genes (e.g., PER1, PER2, NPAS2, MTNR1A, and MTNR1B). The master clock located in the suprachiasmatic nuclei of the hypothalamus synchronizes mainly by light signals, and releases glutamate and pituitary adenylate cyclase-activating polypeptide (PACAP) with the activation of signal transduction cascades, including nNOS activity, cAMP- and cGMP-dependent protein kinases. Additionally, multiple entrainment pathways converge to phosphorylate CREB and to activate CLOCK gene expression [25-27] (see Figure 1 for circadian pathways and related features).

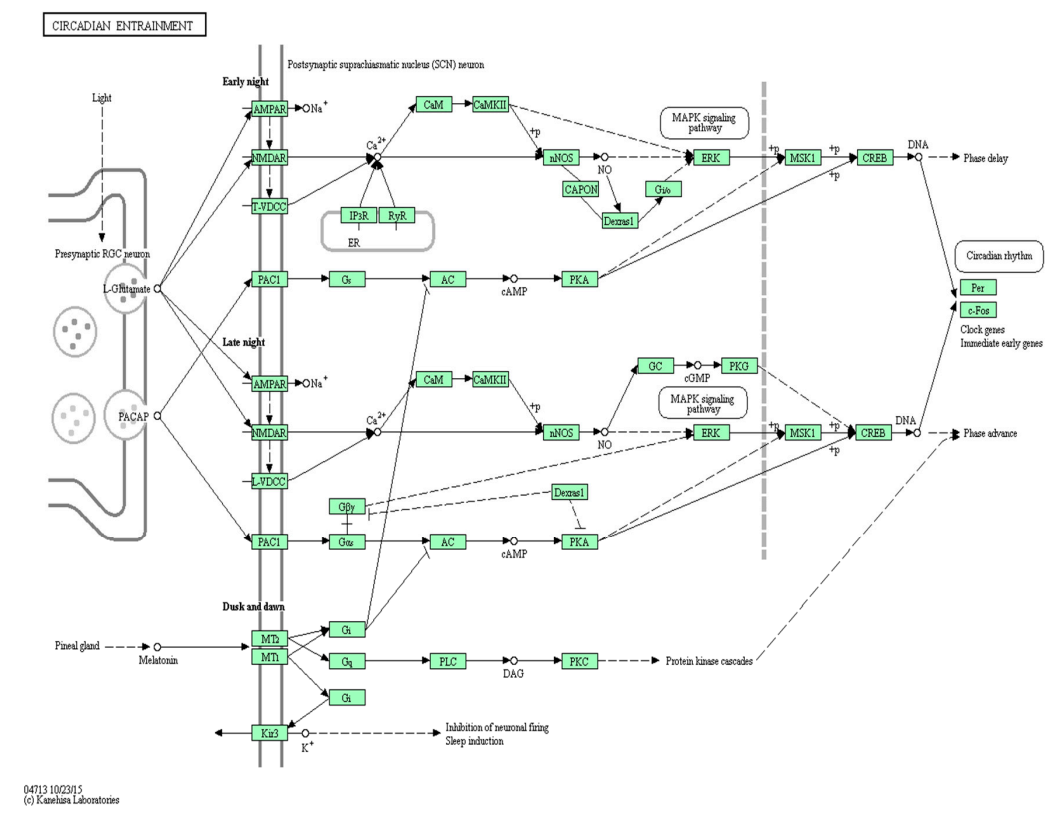

Figure 1. Circadian entrainment is an intrinsic, internal biological clock entrained by exogenous signals, such as endocrine and behavioral rhythms synchronized to environmental cues. The master clock located in the suprachiasmatic nuclei (SCN) of the hypothalamus synchronizes circadian oscillators in peripheral tissues. The main photic input to the suprachiasmatic nuclei comes from the retinal ganglion cells which use glutamate and PACAP, which leads to activation of AMPA and NMDA receptors. The release of glutamate and PACAP triggers the activation of signal transduction cascades including CamKII and nNOS activity, cAMP- and cGMP-dependent protein kinases and mitogen-activated protein kinase (MAPK). Also, melatonin affects non-photic entrainment by inhibiting light-induced phase shifts through inhibition of adenylate cyclase (AC). Additionally, multiple entrainment pathways converge to phosphorylate CREB and to activate CLOCK gene expression [28-31]. Solid and dotted lines indicate direct and indirect relationships, respectively. 
Arousal and cortical responsiveness are modulated by a complex regulatory network including serotonergic feedback from the median raphe nuclei involved in the regulation of rapid eye movement (REM) sleep patterning [24]. Depletion of serotonin receptors and feedback are implicated in the pathology of Sudden infant death syndrome (SIDS), a secondary Superpathway identified in our study [32]. BDNF, a neurotrophic factor, and CHRNA7 genes involved in the SIDS Superpathway were also implicated in the biological processes impacting the response to hypoxia and may reflect underlying vulnerability to neurological/physiological injury secondary to apnea, thereby influencing neurocognition and/or behavior. Mesencephalic dopaminergic neurons from the ventral tegmental area also project to the thalamic nuclei to directly modulate sleep induction and wakefulness through opposing effects of $D R D 1$ and $D R D 2$ receptors on adenylyl cyclase activity.

Neuronal activity and plasticity during brain development is sensitive to both neurotransmitter signaling of serotonin and dopamine and responsive to common genetic and environmental factors influencing brain maturation. Monoamine-sensitive periods also modulate select neurodevelopmental processes (e.g., neuron division, migration and dendritic connectivity) involved in the development of behavioral regulation and control as well as sleep patterns, which may reflect core etiological relationships linking neuropsychiatric illnesses to sleep disruption and hypoxia [28,33-38]. Additionally, the homeostatic value of sleep and circadian rhythmicity impact physiology and behavior in important ways, including the response to stress. Rhythmic circadian oscillations in glucocorticoid levels can modulate adult hippocampal growth and functioning through inhibitory effects of glucocorticoid hormones on neural stem cell and progenitor cell proliferation [39]. Thus, the disruption of circadian entrainment or loss of circadian regulation of glucocorticoid release could directly influence hippocampal neuroplasticity, learning and memory throughout life, which may play a role in psychopathology such as schizophrenia [40,41].

Our analyses are limited by the current status of research and availability of published literature reports on candidate genes as well as the reliability of the curated databases and integrated pathway analyses produced by the GeneAnalytics algorithms. Advances in genomic technology and bioinformatics will continue to identify and characterization new candidate genes, but not all identified genes will be equally important or certain to be causative. The relative contributions of any individual gene to the general disease prevalence must be assessed individually. Further, intrinsic bias in the curated literature may result from imbalances in the allocation of resources for study which may overemphasize some disease states or scientific disciplines over others (e.g., genetics of cancer over psychiatry). Nevertheless, the convergence of these model systems and overlaid genetic mechanisms provides relevant insight into the key macro systems involved in pathogenesis and the overlap of these three severe neuropsychiatric disorders.

\section{Materials and Methods}

We used recently published list of genes found to be clinically relevant and known to play a role in ASD [21], bipolar disorder [22] and schizophrenia [23] for molecular profiling and pathway analysis of genes common to all three neuropsychiatric conditions with similar features. GeneAnalytics (http://geneanalytics.genecards.org/ [20]) computer program and genomic databases are part of the GeneCards Suite developed by LifeMap Sciences (http:/ / www.lifemapsc.com/products/genecardssuite-premium-tools/) and were used to map the resultant list of common genes to characterize molecular pathways, biological processes, molecular functions, phenotypes, tissues and cells, diseases and compounds affected by overlapping neuropsychiatric genes.

GeneAnalytics is powered by GeneCards, LifeMap Discovery, MalaCards and PathCards, which combine $>100$ archived data sources [20]. The databases contain gene lists for tissues and cells, diseases, phenotypes pathways and compounds curated from published literature reports to develop the best matched list of genes, scored and subdivided into their biological categories such as diseases or pathways. These applications are integrated with GeneCards human gene database, Malacards human disease database, PathCards, human biological pathways database, and LifeMap Discovery tissues 
and cells database in order to provide an extensive universe of data from human genes, proteins, cells, biological pathways, diseases and their relationships with integration valuable for research and discovery purposes.

Disease matching scores were derived based upon the number of overlapping genes found and the nature of the gene-disease associations. Tissues and cells were scored using a matching algorithm that weighs tissue specificity, abundance and function of the gene. Related pathways were then grouped into Superpathways to improve inferences and pathway enrichment, reduce redundancy and rank genes within a biological mechanism via the multiplicity of constituent pathways with the methodology and algorithm generated by the GeneAnalytics computer-based program. Superpathways were scored based upon transformation of the binomial $p$-value which was equivalent to a corrected $p$-value with significance defined at $<0.0001$.

\section{Conclusions}

Genetic overlap among autism spectrum disorder, bipolar disorder and schizophrenia was most strongly mapped to Superpathways and brain tissue types guiding Circadian entrainment. The results illustrate the converging effects of dopamine, serotonin and the signal transduction pathways involved in mood, behavior, cognition and impaired social functions; learning and memory are affected in these neuropsychiatric disorders which also guide brain development and sleep patterning disturbances. Thus, under-recognized sleep dysregulation as a common component of psychiatric illness appears to reflect the underlying molecular and genetic architecture of disease pathology in psychiatric illnesses. The convergence of pathways governing circadian rhythms supports the existence of a common core etiological relationship between neuropsychiatric illness and sleep disruption possibly related to central brain stem dysfunction impacting the presentation and underlying pathology and course of illness. This observation opens a new avenue to pursue for treatment modalities in order to change the clinical outcome and natural history of those affected with these relatively common mental health disorders in our current society.

Acknowledgments: We acknowledge support from the Consortium for Translational Research on Aggression and Drug Abuse and Dependence (ConTRADA) grant QB864900 from the University of Kansas and the National Institute of Child Health and Human Development (NICHD) grant HD02528. We thank Miwako Karikomi from Kanehisa Laboratories for granting the permission to publish the Kyoto Encyclopedia of Genes and Genomes (KEGG) pathways map image.

Author Contributions: Naveen Khanzada performed the literature review, compiled information for the GeneAnalytics analysis and primarily composed the manuscript. Merlin Butler contributed to the generation and interpretation of genetic data and the preparation of the manuscript. Ann Manzardo was responsible for the oversight of the study design, implementation, data analysis and interpretation, and manuscript preparation. All of the authors contributed to the final revision and accepted the manuscript.

Conflicts of Interest: The authors declare no conflict of interest.

\section{Abbreviations}

$\begin{array}{ll}\text { ASD } & \text { Autism spectrum disorder } \\ \text { BPD } & \text { Bipolar disorder } \\ \text { SCH } & \text { Schizophrenia } \\ \text { GWAS } & \text { Genome-wide association studies } \\ \text { CGH } & \text { Comparative genomic hybridization } \\ \text { CNV } & \text { Copy number variants } \\ \text { SIDS } & \text { Sudden infant death syndrome } \\ \text { SCN } & \text { Suprachiasmatic nuclei } \\ \text { PACAP } & \text { Pituitary adenylate cyclase-activating polypeptide } \\ \text { CAMP } & \text { Cyclic adenosine monophosphate } \\ \text { CGAMP } & \text { Cyclic guanosine monophosphate-adenosine monophosphate } \\ \text { nNOS } & \text { Nitric oxide synthase } \\ \text { CREB } & \text { cAMP response element-binding protein }\end{array}$




\section{References}

1. American Psychiatric Association. Diagnostic and Statistical Manual of Mental Disorders: DSMIV-TR, 4th ed.; American Psychiatric Association: Washington, DC, USA, 2000.

2. Carroll, L.S.; Owen, M.J. Genetic overlap between autism, schizophrenia and bipolar disorder. Genome Med. 2009, 1, 102. [CrossRef] [PubMed]

3. Burbach, J.; Peter, H.; van der Zwaag, B. Contact in the genetics of autism and schizophrenia. Trends Neurosci. 2009, 32, 69-72. [CrossRef] [PubMed]

4. Sullivan, P.F.; Magnusson, C.; Reichenberg, A.; Boman, M.; Dalman, C.; Davidson, M.; Fruchter, E.; Hultman, C.M.; Lundberg, M.; Långström, N.; et al. Family history of schizophrenia and bipolar disorder as risk factors for autism. Arch. Gen. Psychiatry 2012, 69, 1099-1103. [CrossRef] [PubMed]

5. Sebat, J.; Lakshmi, B.; Malhotra, D.; Troge, J.; Lese-Martin, C.; Walsh, T.; Yamrom, B.; Yoon, S.; Krasnitz, A.; Kendall, J.; et al. Strong association of de novo copy number mutations with autism. Science 2007, 316, 445-449. [CrossRef] [PubMed]

6. Szatmari, P.; Paterson, A.D.; Zwaigenbaum, L.; Roberts, W.; Brian, J.; Liu, X.Q.; Vincent, J.B.; Skaug, J.L.; Thompson, A.P.; Senman, L.; et al. Autism Genome Project Consortium, Mapping autism risk loci using genetic linkage and chromosomal rearrangments. Nat. Genet. 2007, 39, 319-328. [CrossRef] [PubMed]

7. Marshall, C.R.; Noor, A.; Vincent, J.B.; Lionel, A.C.; Feuk, L.; Skaug, J.; Shago, M.; Moessner, R.; Pinto, D.; Ren, Y.; et al. Structural variation of chromosomes in autism spectrum disorder. Am. J. Hum. Genet. 2008, 82, 477-488. [CrossRef] [PubMed]

8. Kim, H.G.; Kishikawa, S.; Higgins, A.W.; Seong, I.S.; Donovan, D.J.; Shen, Y.; Lally, E.; Weiss, L.A.; Najm, J.; Kutsche, K.; et al. Disruption of neurexin 1 associated with autism spectrum disorder. Am. J. Hum. Genet. 2008, 82, 199-207. [CrossRef] [PubMed]

9. Belmonte, M.K.; Bourgeron, T. Fragile $X$ syndrome and autism at the intersection of genetic and neural networks. Nat. Neurosci. 2006, 9, 1221-1225. [CrossRef] [PubMed]

10. Kwon, C.H.; Luikart, B.W.; Powell, C.M.; Zhou, J.; Matheny, S.A.; Zhang, W.; Li, Y.; Baker, S.J.; Parada, L.F. Pten regulates neuronal arborization and social interaction in mice. Neuron 2006, 50, 377-388. [CrossRef] [PubMed]

11. Hoeffer, C.A.; Tang, W.; Wong, H.; Santillan, A.; Patterson, R.J.; Martinez, L.A.; Tejada-Simon, M.V.; Paylor, R.; Hamilton, S.L.; Klann, E. Removal of FKBP12 enhances mTOR-Raptor interactions, LTP, memory, and perseverative/repetitive behavior. Neuron 2008, 60, 832-845. [CrossRef] [PubMed]

12. Cuscó, I.; Medrano, A.; Gener, B.; Vilardell, M.; Gallastegui, F.; Villa, O.; González, E.; Rodríguez-Santiago, B.; Vilella, E.; del Campo, M.; et al. Autism-specific copy number variants further implicate the phosphatidylinositol signaling pathway and the glutamatergic synapse in the etiology of the disorder. Hum. Mol. Genet. 2009, 18, 1795-1804. [CrossRef] [PubMed]

13. Emamian, E.S.; Hall, D.; Birnbaum, M.J.; Karayiorgou, M.; Gogos, J.A. Convergent evidence for impaired AKT1-GSK3 $\beta$ signaling in schizophrenia. Nat. Genet. 2004, 36, 131-137. [CrossRef] [PubMed]

14. Stopkova, P.; Saito, T.; Papolos, D.F.; Vevera, J.; Paclt, I.; Zukov, I.; Bersson, Y.B.; Margolis, B.A.; Strous, R.D.; Lachman, H.M. Identification of PIK3C3 promoter variant associated with bipolar disorder and schizophrenia. Biol. Psychiatry 2004, 55, 981-988. [CrossRef] [PubMed]

15. Kalkman, H.O. The role of the phosphatidylinositide 3-kinase-protein kinase B pathway in schizophrenia. Pharmacol. Ther. 2006, 110, 117-134. [CrossRef] [PubMed]

16. Krivosheya, D.; Tapia, L.; Levinson, J.N.; Huang, K.; Kang, Y.; Hines, R.; Ting, A.K.; Craig, A.M.; Mei, L.; Bamji, S.X.; et al. ErbB4-neuregulin signaling modulates synapse development and dendritic arborization through distinct mechanisms. J. Biol. Chem. 2008, 283, 32944-32956. [CrossRef] [PubMed]

17. Cox, D.M.; Butler, M.G. The 15q11.2 BP1-BP2 microdeletion syndrome: A review. Int. J. Mol. Sci. 2015, 16, 4068-4082. [CrossRef] [PubMed]

18. Burnside, R.D.; Pasion, R.; Mikhail, F.M.; Carroll, A.J.; Robin, N.H.; Youngs, E.L.; Gadi, I.K.; Keitges, E.; Jaswaney, V.L.; Papenhausen, P.R.; et al. Microdeletion/microduplication of proximal 15q11.2 between BP1 and BP2: A susceptibility region for neurological dysfunction including developmental and language delay. Hum. Genet. 2011, 130, 517-528. [CrossRef] [PubMed] 
19. Ho, K.S.; Wassman, E.R.; Baxter, A.L.; Hensel, C.H.; Martin, M.M.; Prasad, A.; Twede, H.; Vanzo, R.J.; Butler, M.G. Chromosomal microarray analysis of consecutive individuals with autism spectrum disorders using an ultra-high resolution chromosomal microarray optimized for neurodevelopmental disorders. Int. J. Mol. Sci. 2016, 17, 2070. [CrossRef] [PubMed]

20. Ben-Ari, F.S.; Lieder, I.; Stelzer, G.; Mazor, Y.; Buzhor, E.; Kaplan, S.; Bogoch, Y.; Plaschkes, I.; Shitrit, A.; Rappaport, N.; et al. GeneAnalytics: An integrative gene set analysis tool for next generation sequencing, RNAseq and microarray data. OMICS J. Integr. Biol. 2016, 20, 139-151. [CrossRef] [PubMed]

21. Butler, M.G.; Rafi, S.K.; Manzardo, A.M. High-resolution chromosome ideogram representation of currently recognized genes for autism spectrum disorders. Int. J. Mol. Sci. 2015, 16, 6464-6495. [CrossRef] [PubMed]

22. Douglas, L.N.; McGuire, A.B.; Manzardo, A.M.; Butler, M.G. High-resolution chromosome ideogram representation of recognized genes for bipolar disorder. Gene 2016, 586, 136-147. [CrossRef] [PubMed]

23. Butler, M.G.; McGuire, A.B.; Masoud, H.; Manzardo, A.M. Currently recognized genes for schizophrenia: High-resolution chromosome ideogram representation. Am. J. Med. Genet. B Neuropsychiatr. Genet. Part B 2016, 1B, 181-202. [CrossRef] [PubMed]

24. Weber, F.; Chung, S.; Beier, K.T.; Xu, M.; Luo, L.; Dan, Y. Control of REM sleep by ventral medulla GABAergic neurons. Nature 2015, 526, 435-438. [CrossRef] [PubMed]

25. Reischl, S.; Kramer, A. Kinases and phosphatases in the mammalian circadian clock. FEBS Lett. 2011, 585, 1393-1399. [CrossRef] [PubMed]

26. Yin, L.; Wang, J.; Klein, P.S.; Lazar, M.A. Nuclear receptor Rev-Erb $\alpha$ is a critical lithium-sensitive component of the circadian clock. Science 2006, 311, 1002-1005. [CrossRef] [PubMed]

27. Zeidner, L.C.; Buescher, J.L.; Phiel, C.J. A novel interaction between Glycogen Synthase Kinase-3 $\alpha$ (GSK-3 $\alpha)$ and the scaffold protein receptor for activated C-Kinase 1 (RACK1) regulates the circadian clock. Int. J. Biochem. Mol. Biol. 2011, 2, 318-327. [PubMed]

28. Tarazi, F.I.; Tomasini, E.C.; Baldessarini, R.J. Postnatal development of dopamine D4-like receptors in rat forebrain regions: Comparison with D2-like receptors. Brain Res. Dev. Brain Res. 1998, 110, 227-233. [CrossRef]

29. Kanehisa, M.; Furumichi, M.; Tanabe, M.; Sato, Y.; Morishima, K. KEGG: New perspectives on genomes, pathways, diseases and drugs. Nucleic Acids Res. 2017, 45, D353-D361. [CrossRef] [PubMed]

30. Kanehisa, M.; Sato, Y.; Kawashima, M.; Furumichi, M.; Tanabe, M. KEGG as a reference resource for gene and protein annotation. Nucleic Acids Res. 2016, 44, D457-D462. [CrossRef] [PubMed]

31. Kanehisa, M.; Goto, S. KEGG: Kyoto Encyclopedia of Genes and Genomes. Nucleic Acids Res. 2000, 28, 27-30. [CrossRef] [PubMed]

32. Lavezzi, A.M.; Casale, V.; Oneda, R.; Weese-Mayer, D.E.; Matturri, L. Sudden infant death syndrome and sudden intrauterine unexplained death: Correlation between hypoplasia of raphé nuclei and serotonin transporter gene promoter polymorphism. Pediatr. Res. 2009, 66, 22-27. [CrossRef] [PubMed]

33. Severson, C.A.; Wang, W.; Pieribone, V.A.; Dohle, C.I.; Richerson, G.B. Midbrain serotoninergic neurons are central pH chemoreceptors. Nat. Neurosci. 2003, 6, 1139-1140. [CrossRef] [PubMed]

34. Gaspar, P.; Cases, O.; Maroteaux, L. The developmental role of serotonin: News from mouse molecular genetics. Nat. Rev. Neurosci. 2003, 4, 1002-1012. [CrossRef] [PubMed]

35. Haydon, P.G.; McCobb, D.P.; Kater, S.B. Serotonin selectively inhibits growth cone motility and synaptogenesis of specific identified neurons. Science 1984, 226, 561-564. [CrossRef] [PubMed]

36. Lauder, J.M. Ontogeny of the serotonergic system in the rat: Serotonin as a developmental signal. Ann. N. Y. Acad. Sci. 1990, 600, 297-313. [CrossRef] [PubMed]

37. McCarthy, D.; Lueras, P.; Bhide, P.G. Elevated dopamine levels during gestation produce region-specific decreases in neurogenesis and subtle deficits in neuronal numbers. Brain Res. 2007, 1182, 11-25. [CrossRef] [PubMed]

38. Popolo, M.; McCarthy, D.M.; Bhide, P. Influence of dopamine on precursor cell proliferation and differentiation in the embryonic mouse telencephalon. Dev. Neurosci. 2004, 26, 229-244. [CrossRef] [PubMed]

39. Fitzsimons, C.P.; Herbert, J.; Schouten, M.; Meijer, O.C.; Lucassen, P.J.; Lightman, S. Circadian and ultradian glucocorticoid rhythmicity: Implications for the effects of glucocorticoids on neural stem cells and adult hippocampal neurogenesis. Front. Neuroendocrinol. 2016, 41, 44-58. [CrossRef] [PubMed] 
40. Tam, S.K.; Pritchett, D.; Brown, L.A.; Foster, R.G.; Bannerman, D.M.; Peirson, S.N. Sleep and circadian rhythm disruption and recognition memory in schizophrenia. Methods Enzymol. 2015, 552, 325-349. [PubMed]

41. Iyer, R.; Wang, T.A.; Gillette, M.U. Circadian gating of neuronal functionality: A basis for iterative metaplasticity. Front. Syst. Neurosci. 2014, 8, 164. [CrossRef] [PubMed]

(C) 2017 by the authors. Licensee MDPI, Basel, Switzerland. This article is an open access article distributed under the terms and conditions of the Creative Commons Attribution (CC BY) license (http:/ / creativecommons.org/licenses/by/4.0/). 